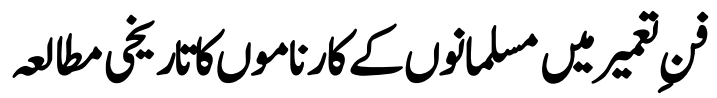

\section{Historical study of Architectural deeds of Muslims}

\section{ABSTRACT}

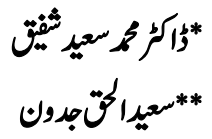

The rise of Muslims is not only worthy example for the world among the countless features but it is also a good example of constructive as well as intellectual development.

The glorious history of Islamic development of science and arts covers the early stages of Islam and lasts till the $18^{\text {th }}$ century which is the longest period. The popularity of Islamic science and arts and discoveries are spread all over the world.

Muslims not only gave first priority to the justice, education and learning during their reign but on other hand they also kept their attention on the intellectual and physical development, science and arts and awesome constructions, that is why in the past the development and progress of medicine and science is exemplary for the world, which is admitted by the experts of art and architecture.

After the age of the Companions of Messenger of Allah Ummayyed constructed mosques in Kufa and Damascus, Bannu Abbas constructed Qurtaba's mosque, bungalow of Khamra and Fatmi rulers built Mahdia and Qahra, which are the most significant and memorable deeds of fine arts.

In this article the fantastic contribution of Muslims in the field of arts and architecture will be reviewed which will make it clear that this sector (Arts and Architecture) was also on track for growth and development like other sectors during the rules of Muslims and they performed such a feats in this field that even an advanced man of today is astonished by watching these feats.

Key Words: Intellectual development, Architecture, Ummayyed, Bannu Abbas

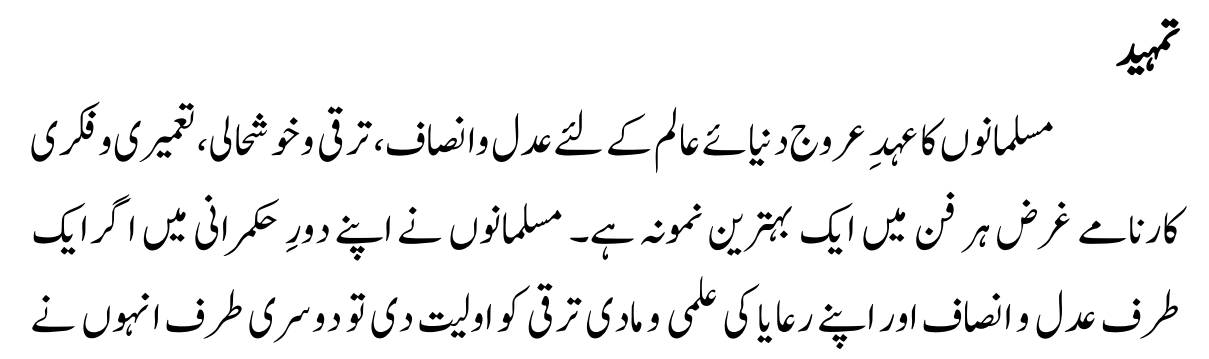

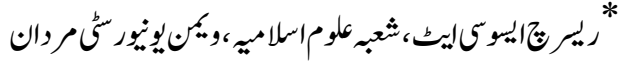

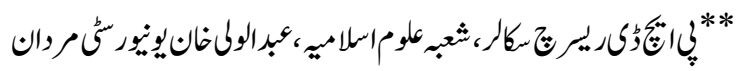




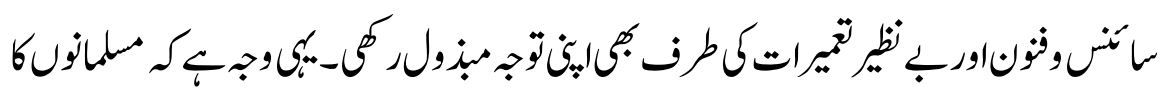

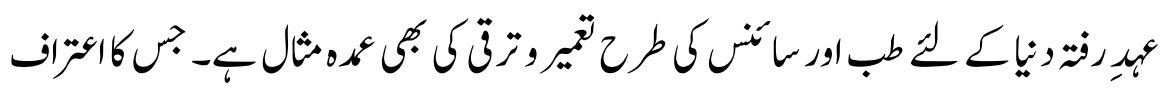

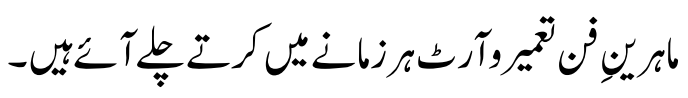

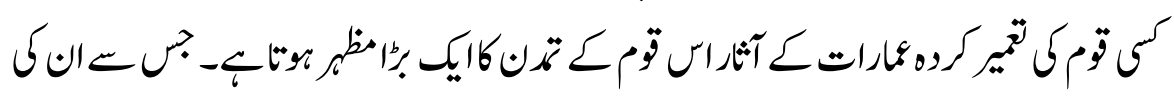

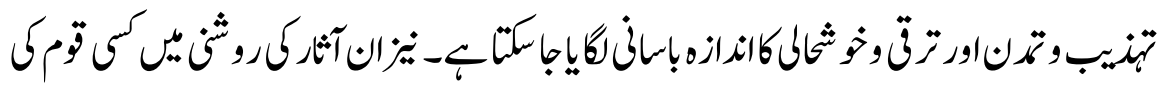

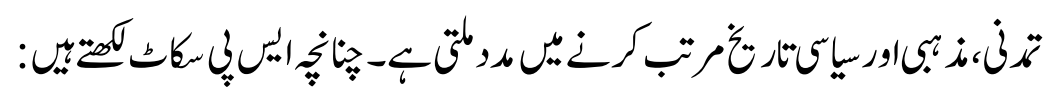

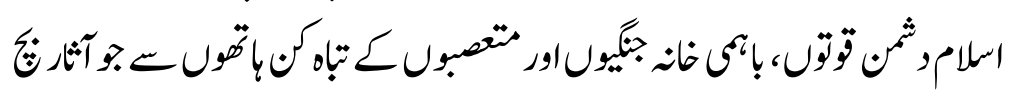

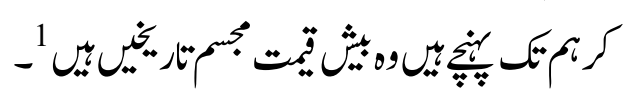

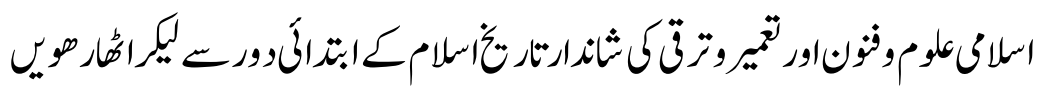

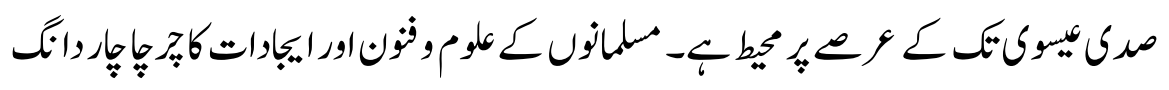

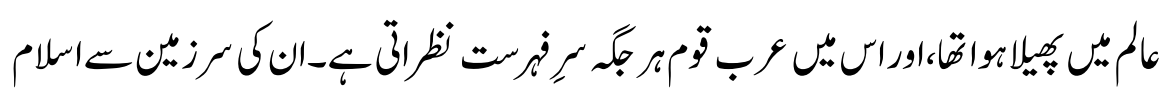

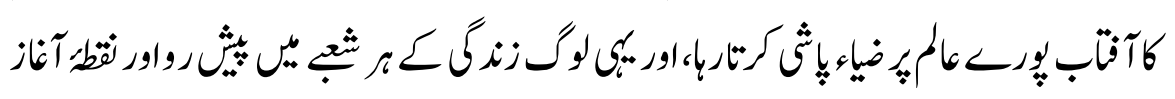

\section{4

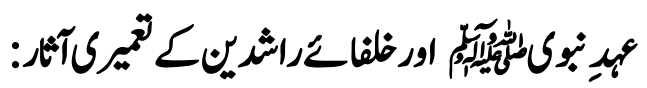

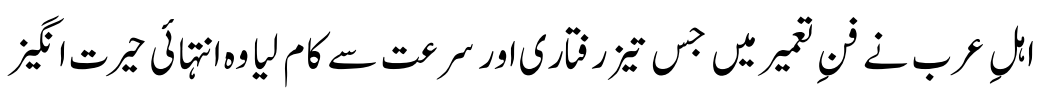

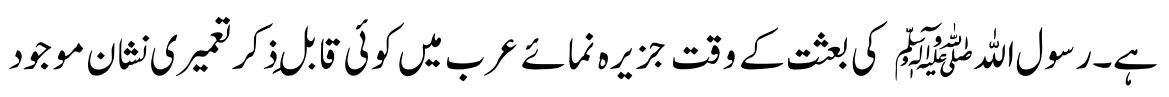

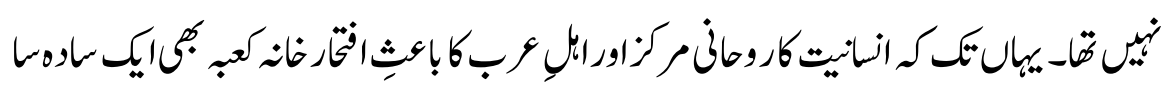

مكان تمات

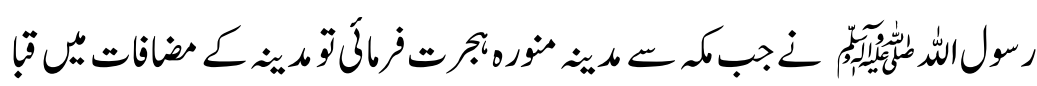

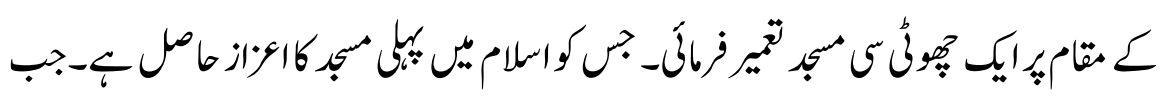

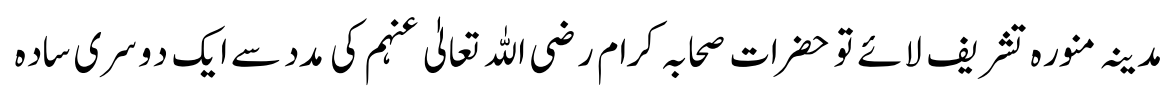

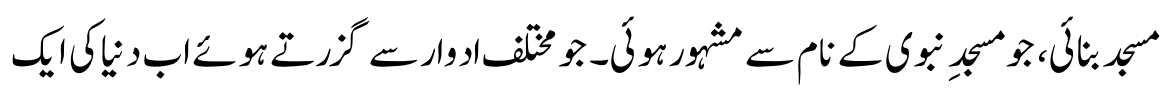




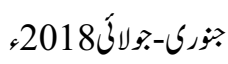

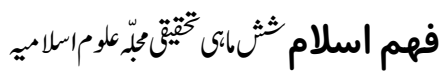

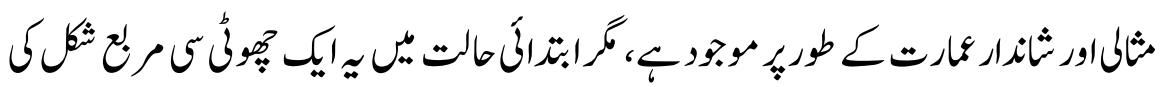

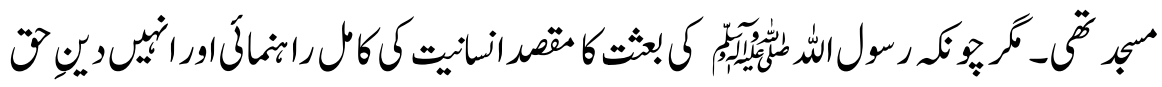

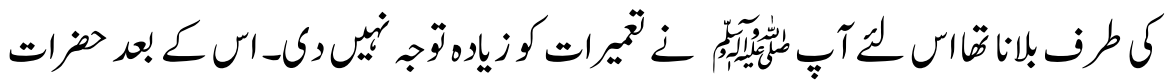

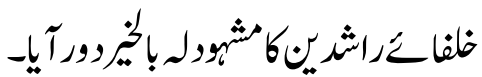

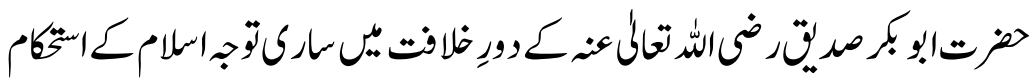

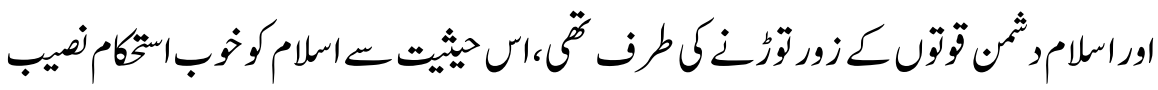

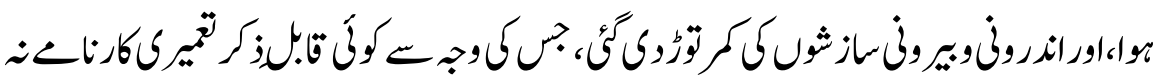

-

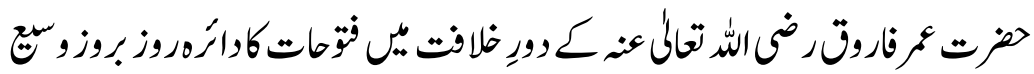

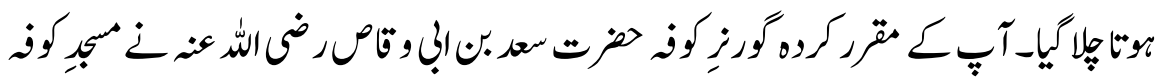

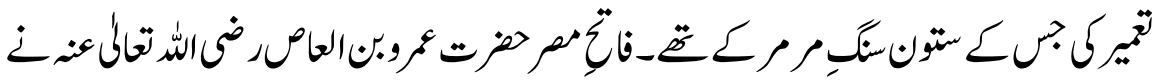

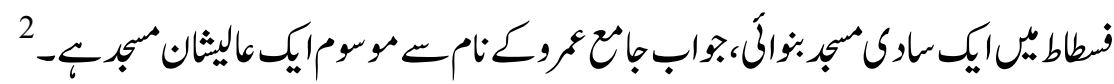

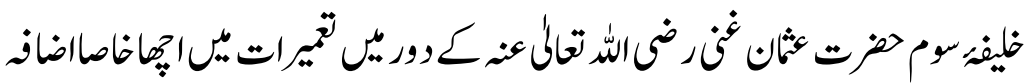

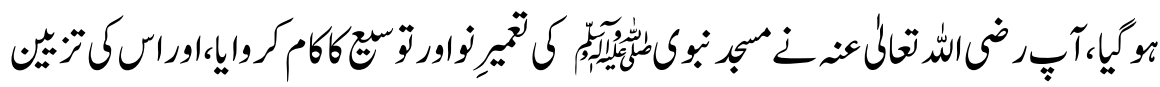

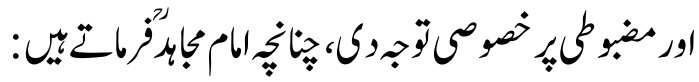

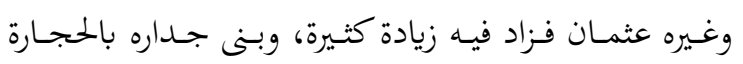

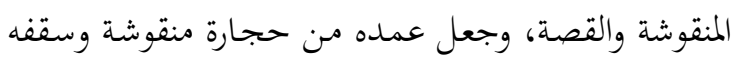

بالساج

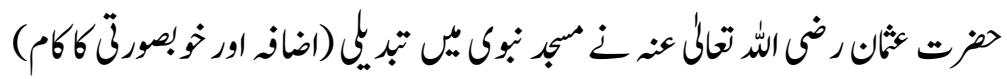

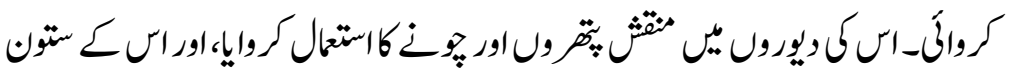

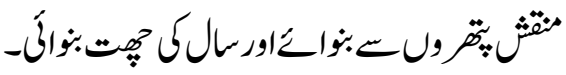

80 


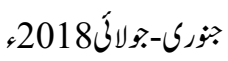

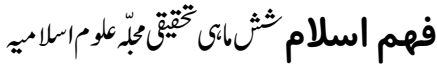

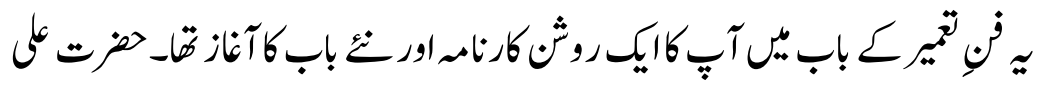

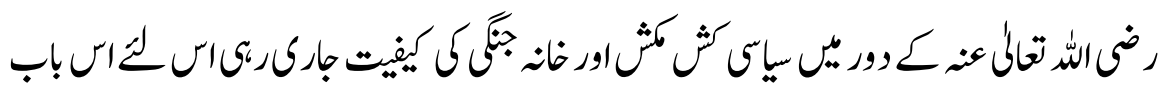

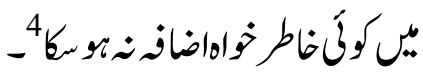

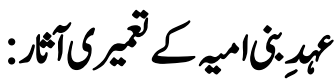

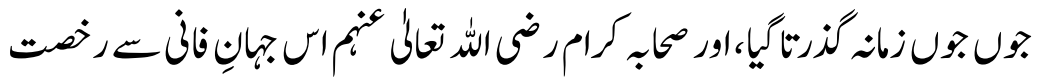

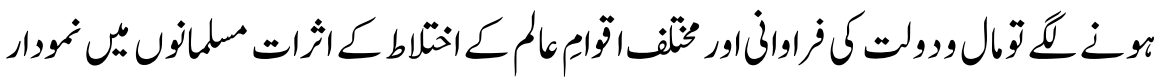

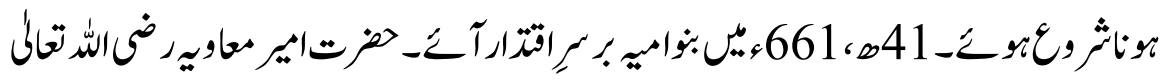

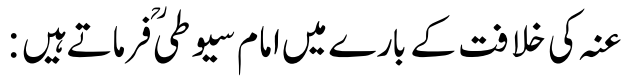

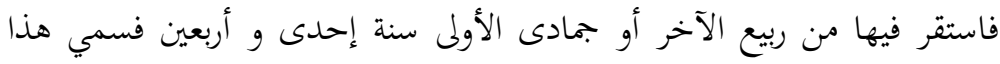

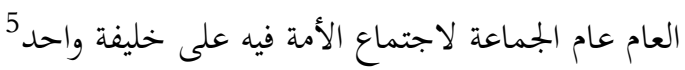

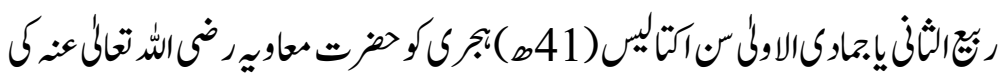

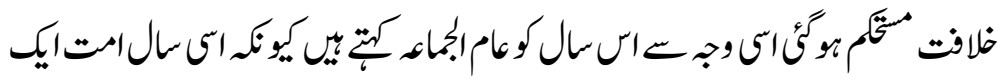

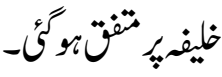

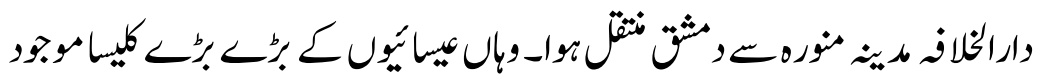

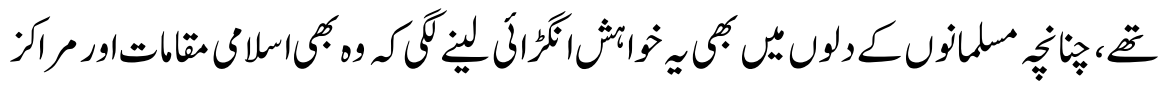

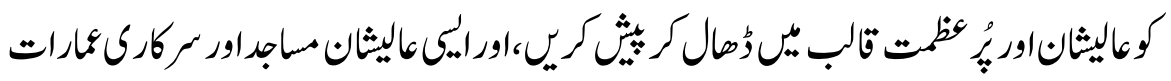

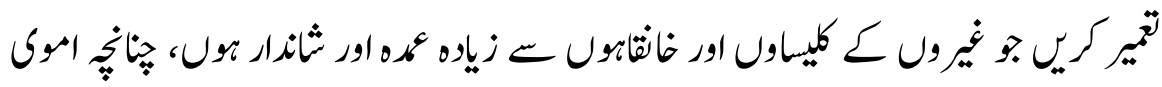

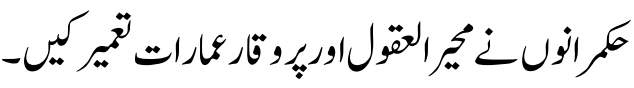

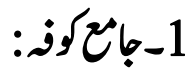

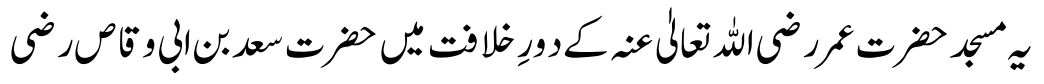

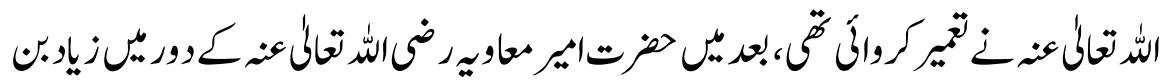

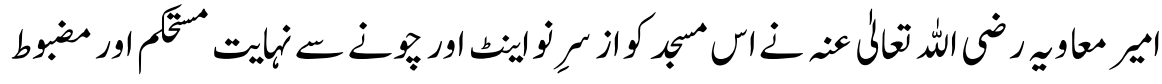

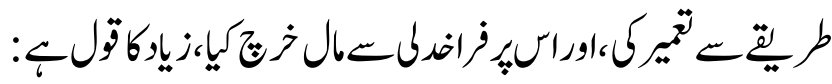

81 
انفقت على كل أسطوانة من أساطين مسجد الكوفة ثمان عشرة مئة.

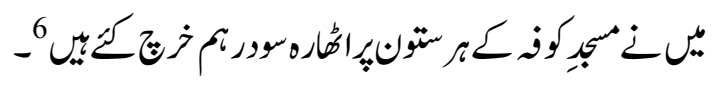

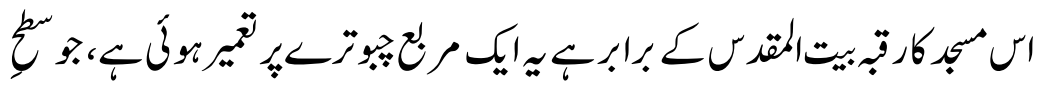

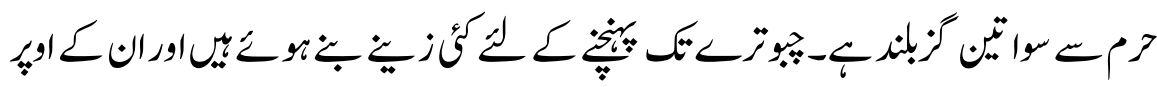

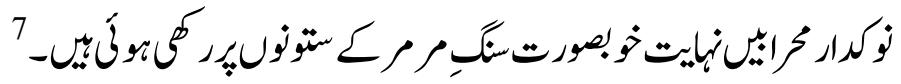

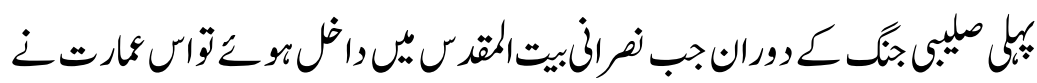

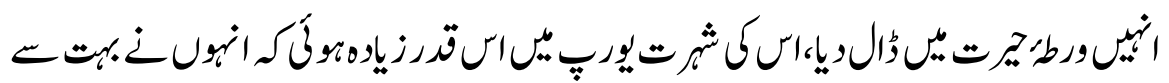

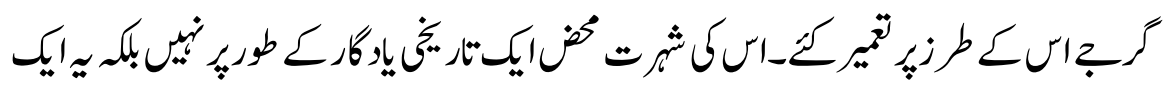

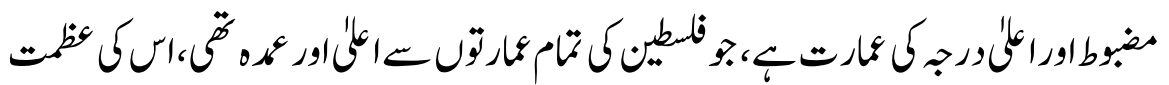

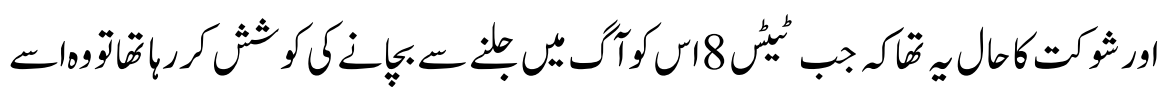

$$
9
$$

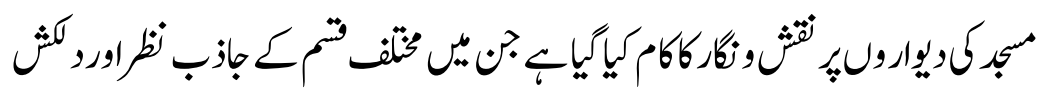

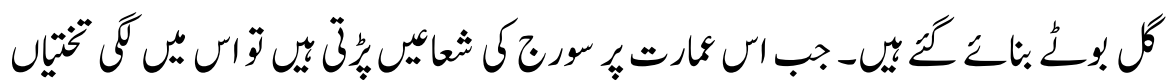

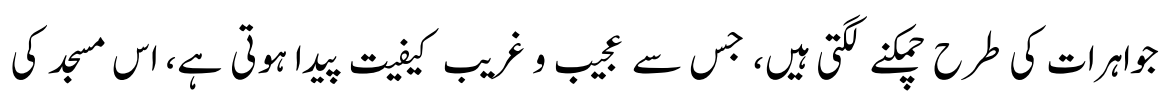

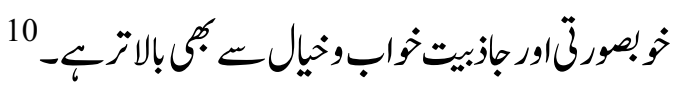

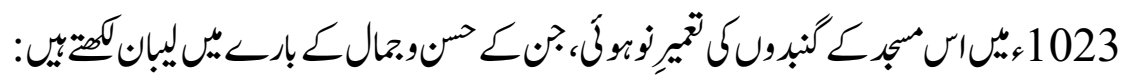

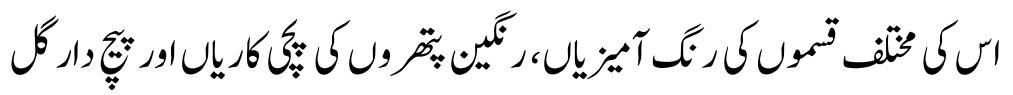

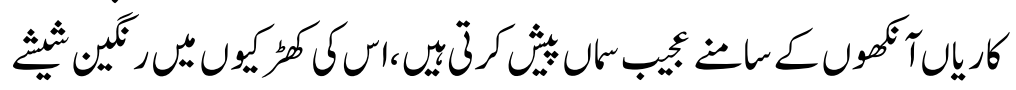

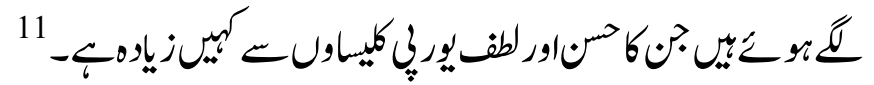

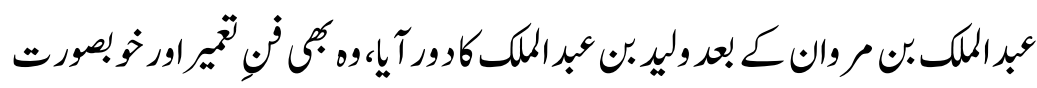

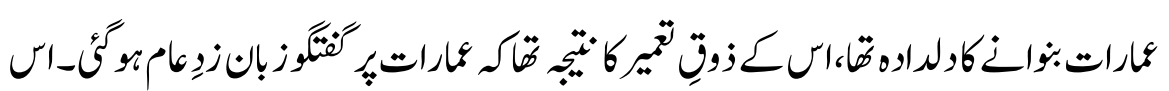

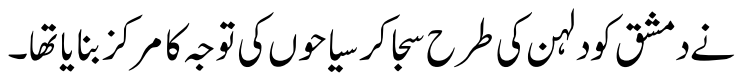




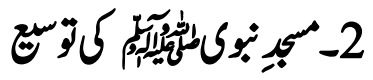

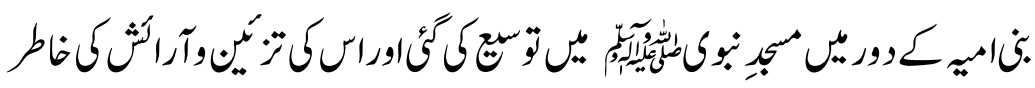

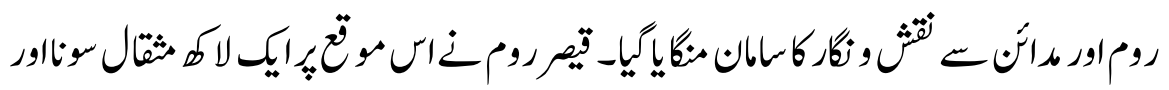

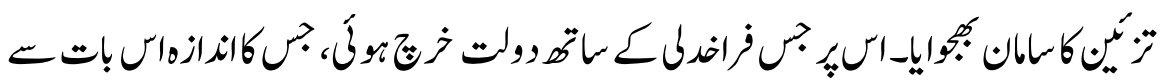

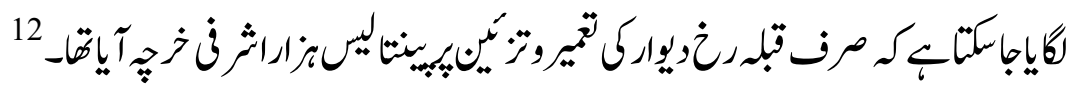

\section{3ـجإعمبروثن(بامعاموى)}

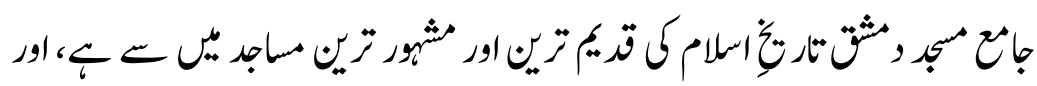

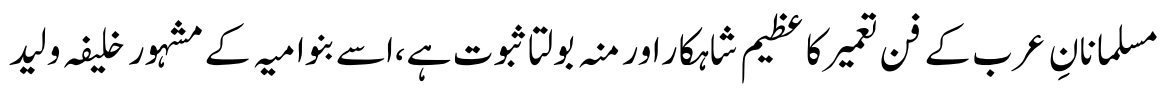

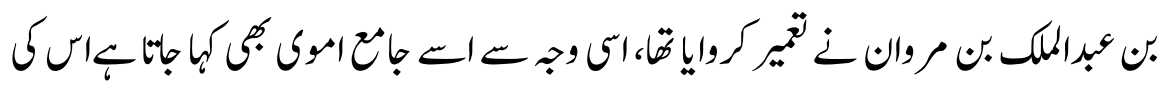

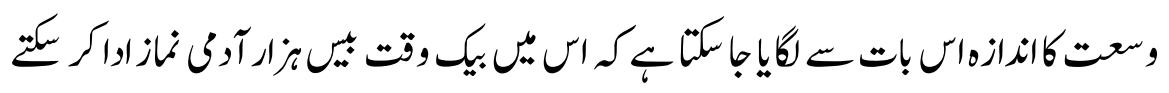

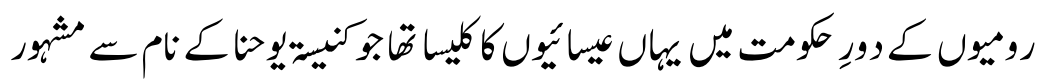

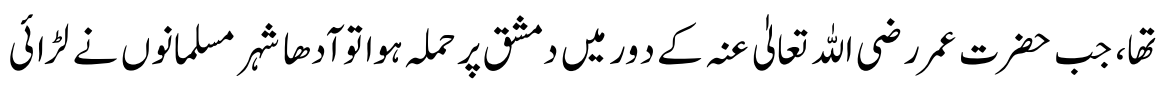

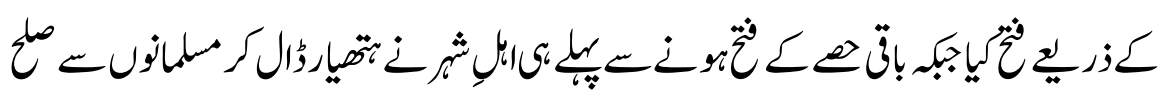

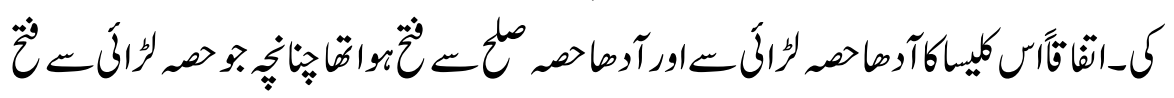

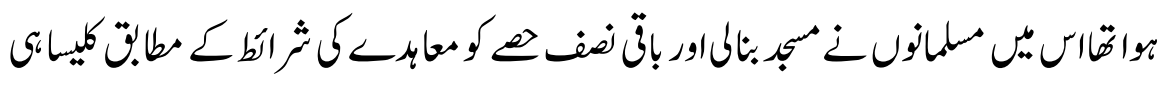

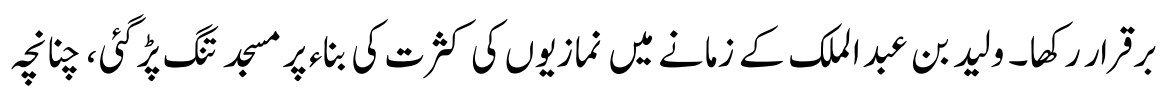

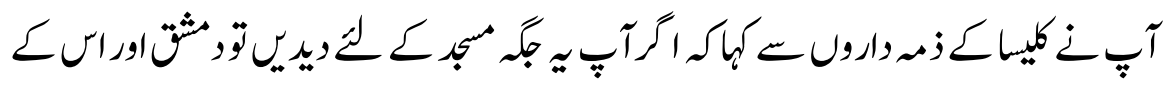

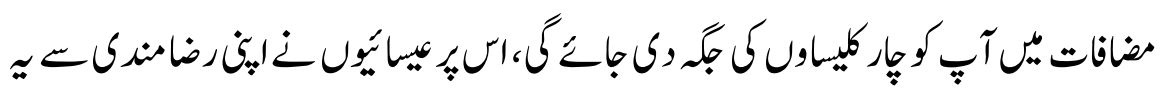

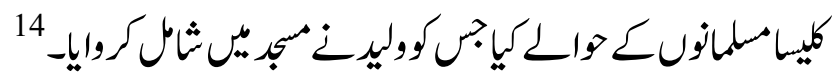

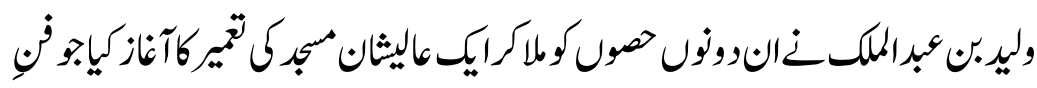

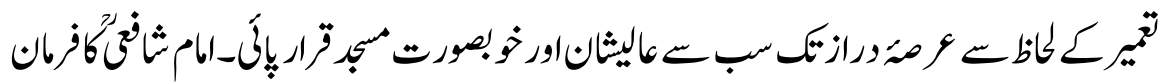




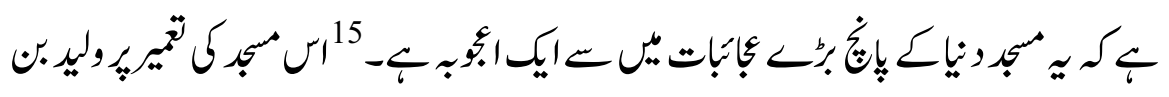

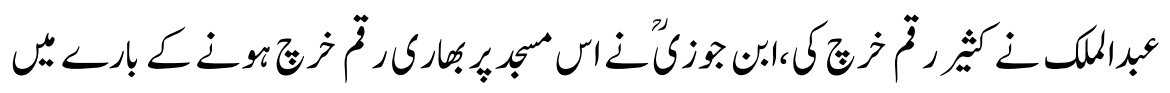
تخريزاياك:

وفي سنة ثمان وثمانين بنى الوليد مسجد دمشق فانفق عليه مالا

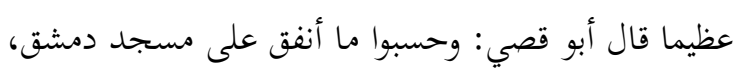

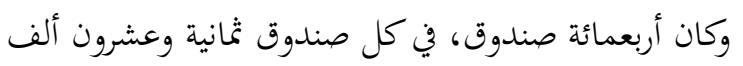

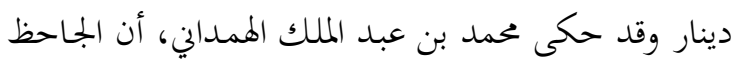

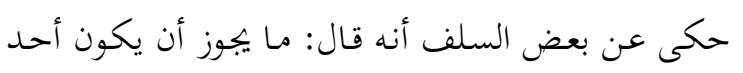

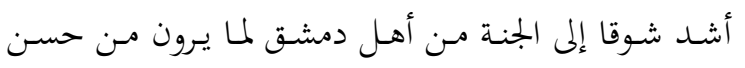
مسجدهم 16.

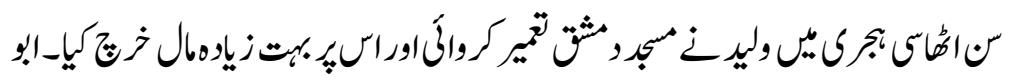

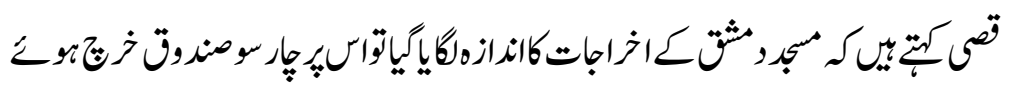

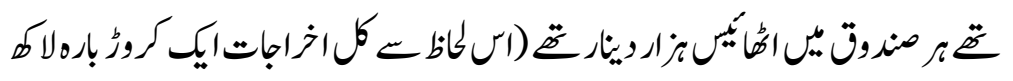

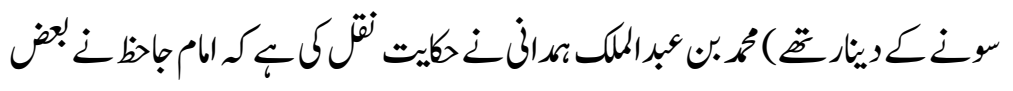

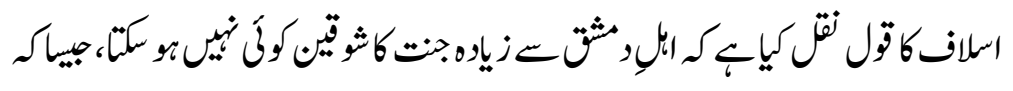

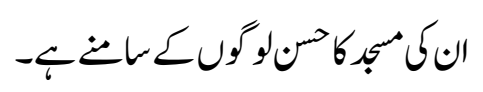

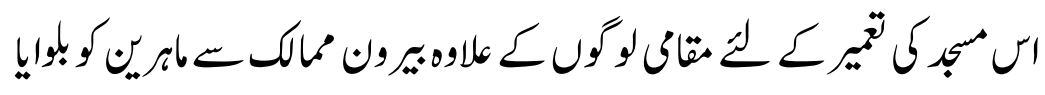

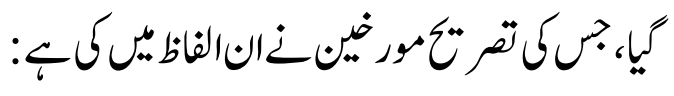
واحتمل له الصناع من بلاد الروم، ومن سائر بلاد الإسلام 17

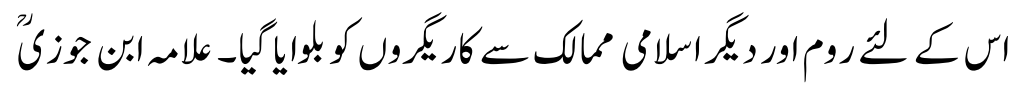
تخريزناستيّ:

وعمل هذا الجامع في تسع سنين،حسبوا ما انفق على الكرمة التي في قبلة مسجد دمشق فكانت سبعين ألف دينار 18. 


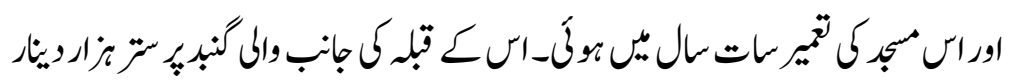

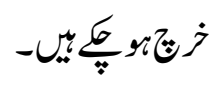

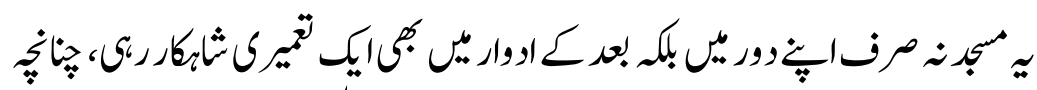

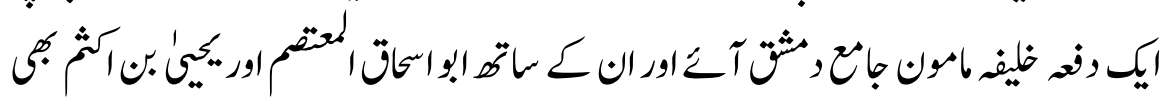

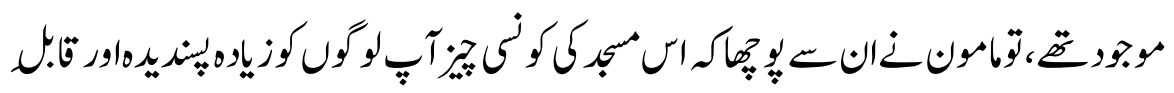

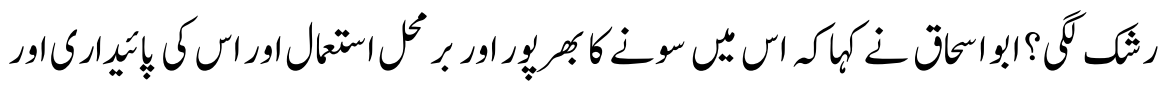

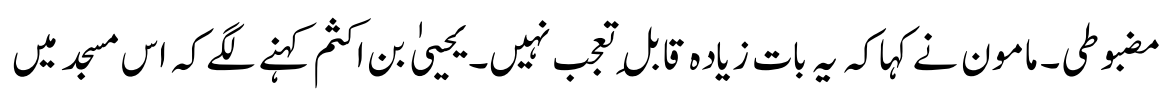

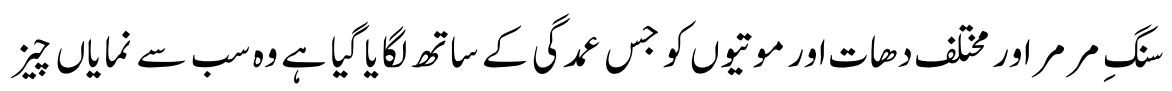

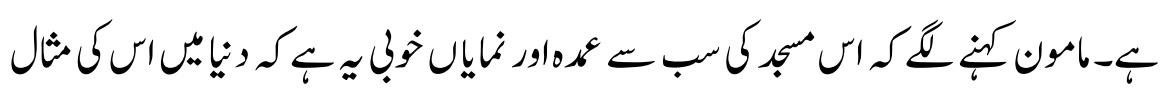

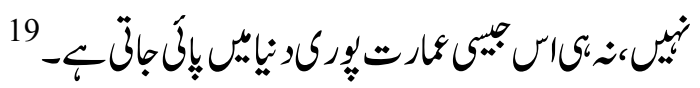

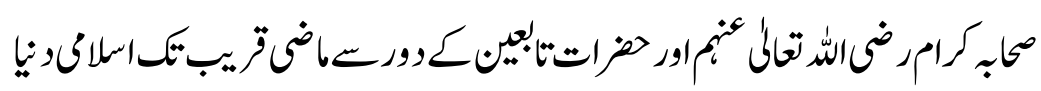

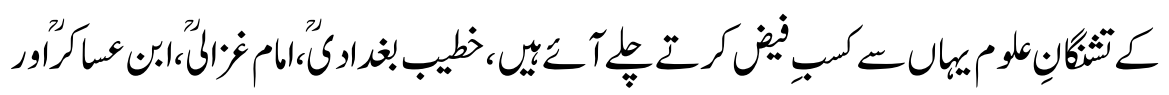

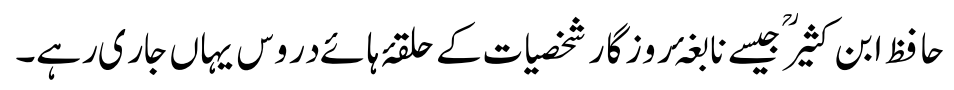

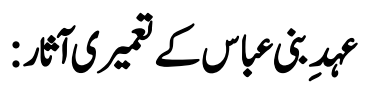

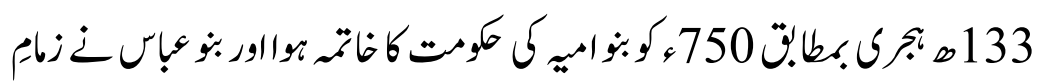

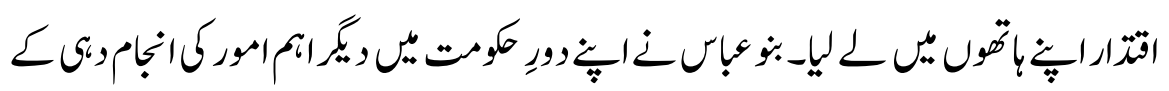

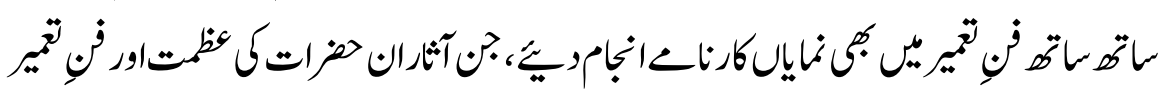

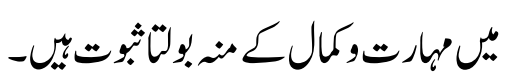
1 مسبرِطب

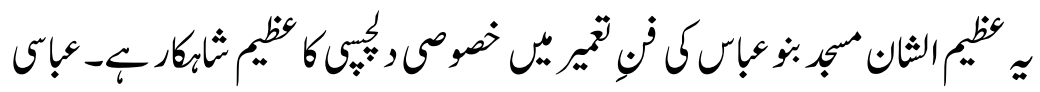

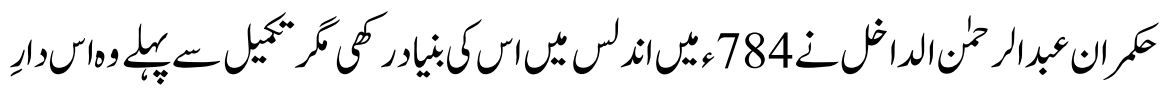

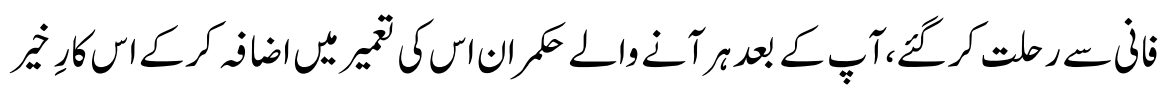




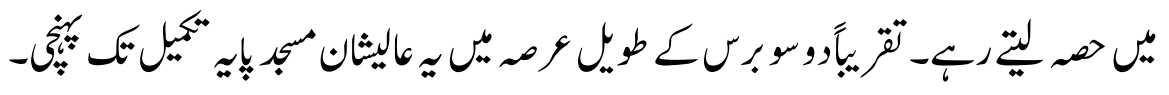

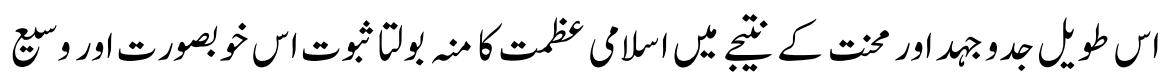

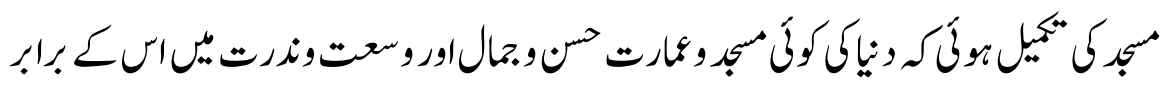

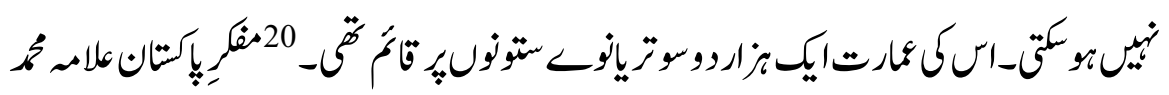

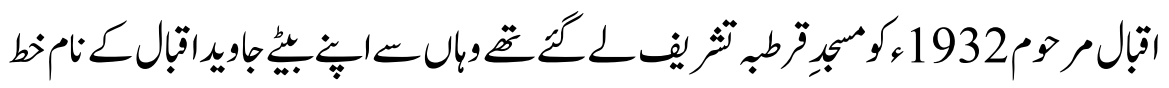

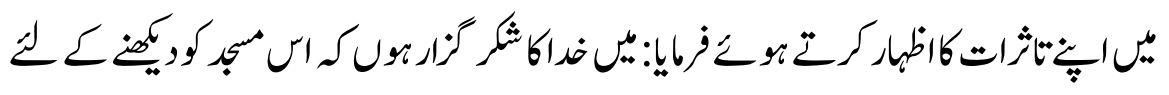

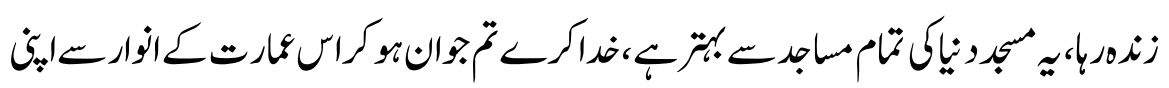

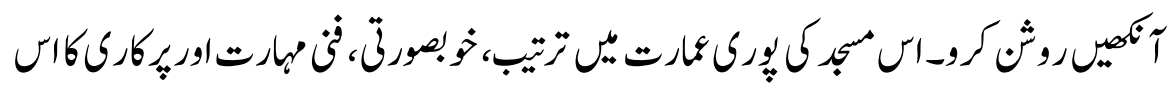

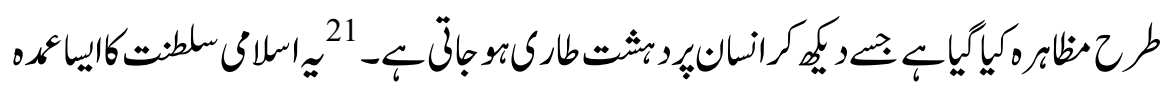

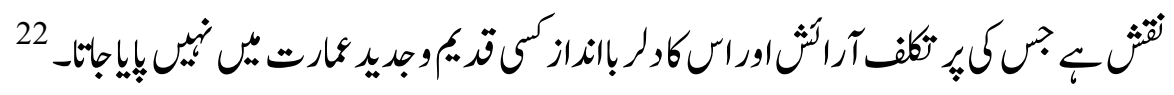

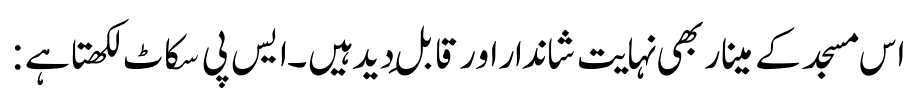

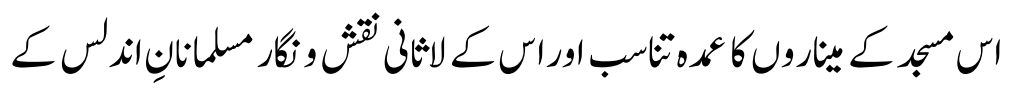

23

$$
\text { 2ـقترازيراء }
$$

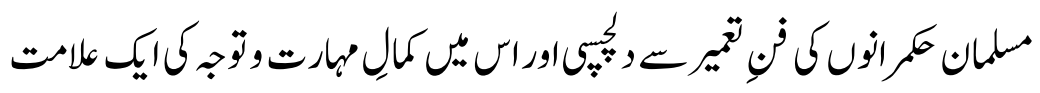

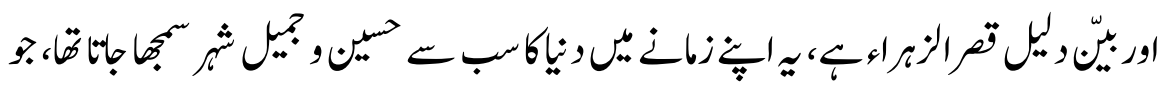

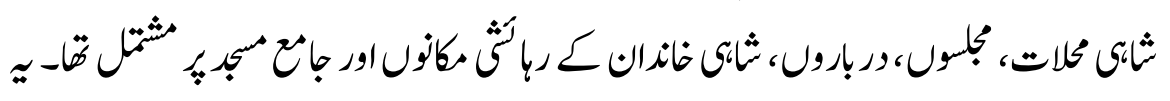

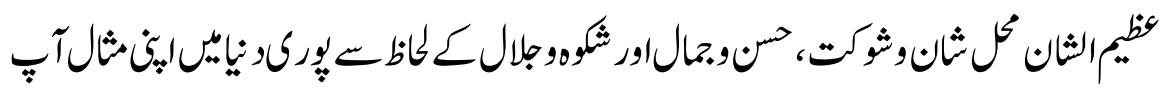

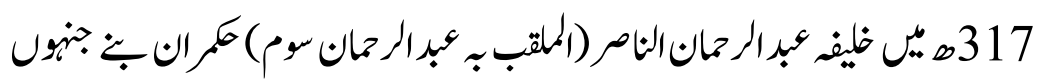

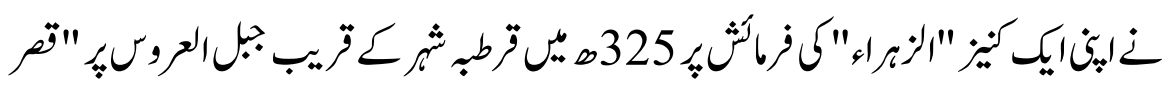

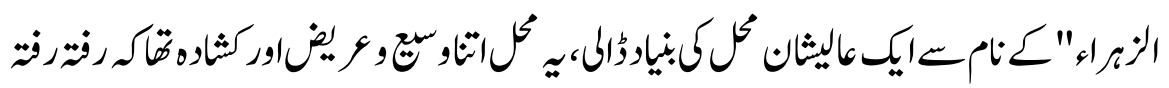




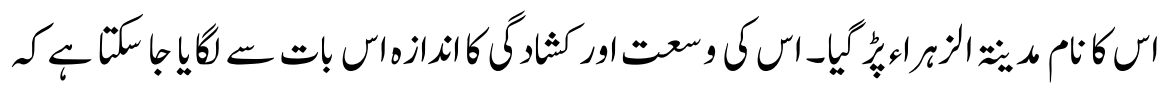

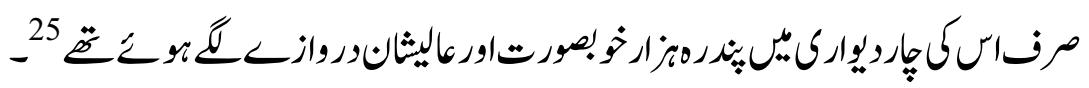

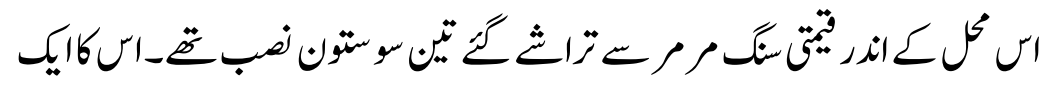

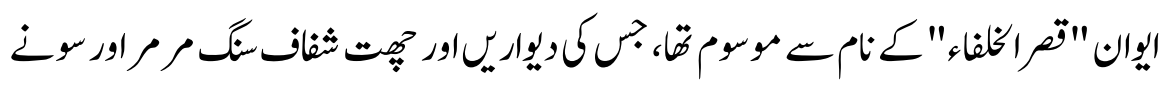

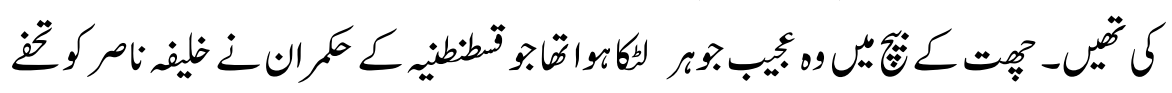

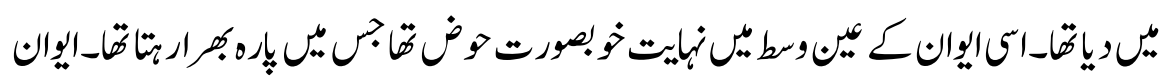

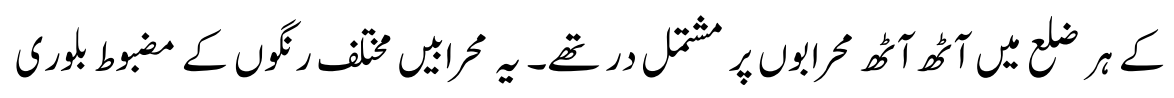

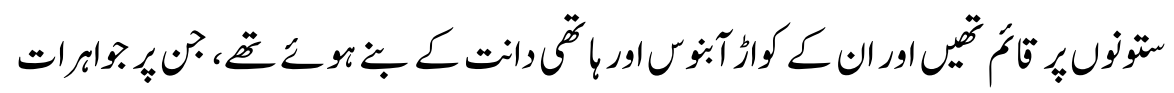

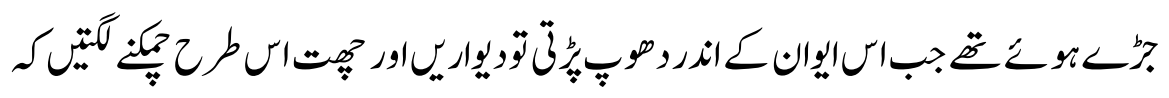

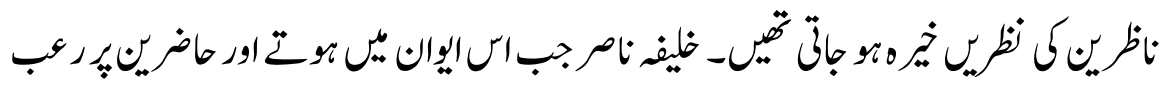

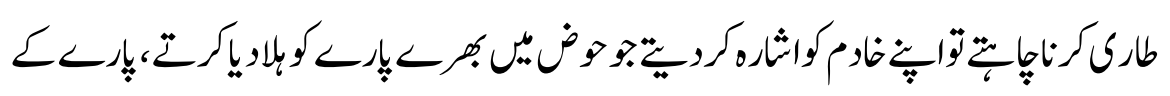

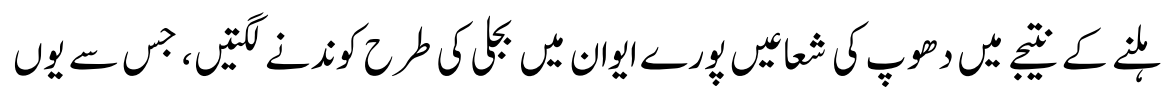

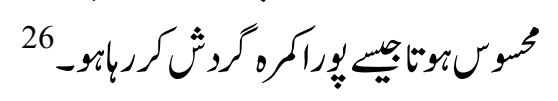

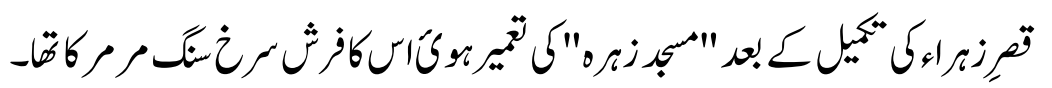

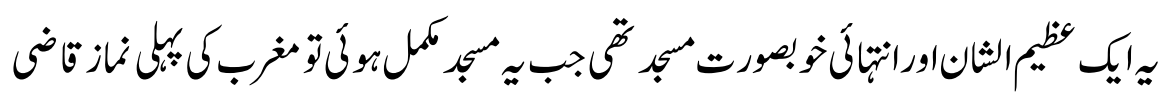

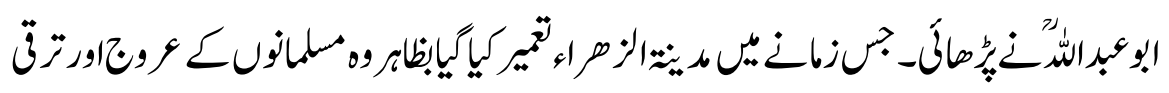

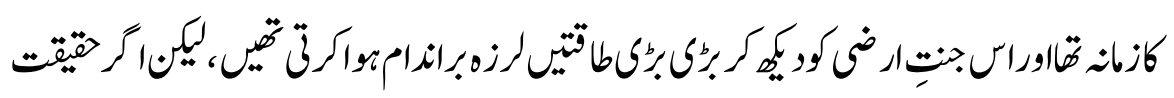

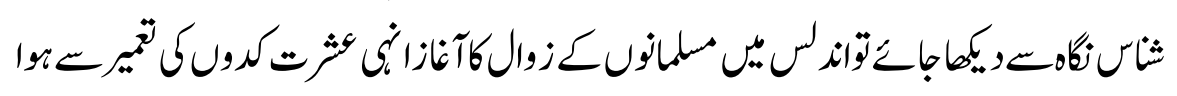

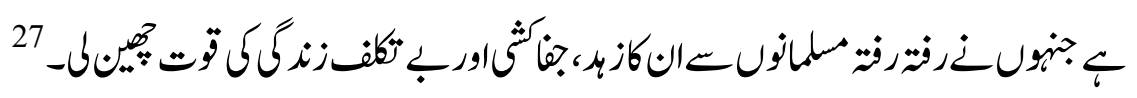

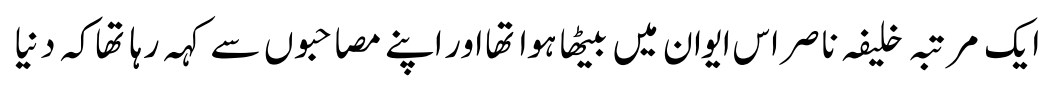

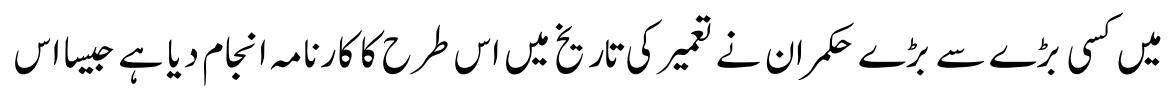

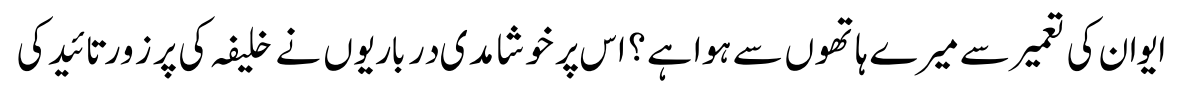




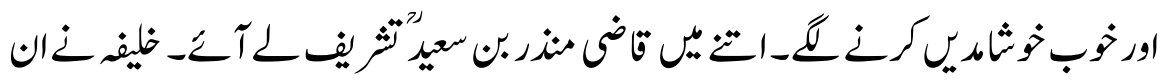

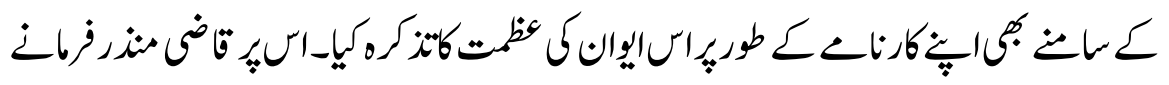

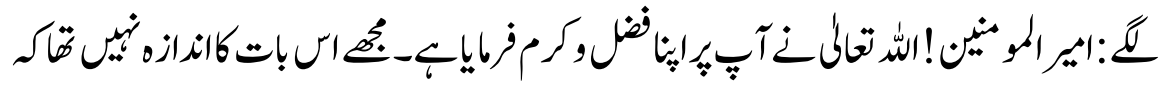

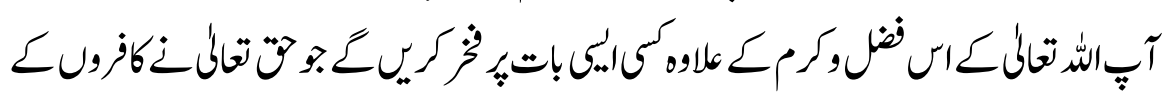

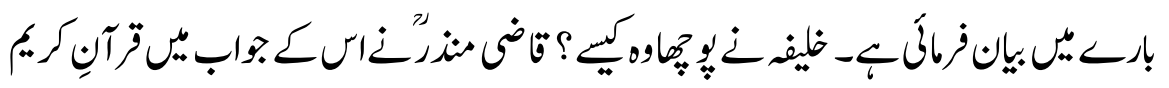

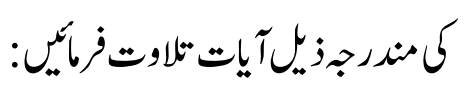

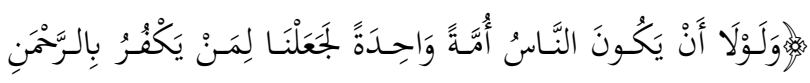

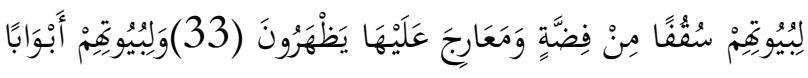

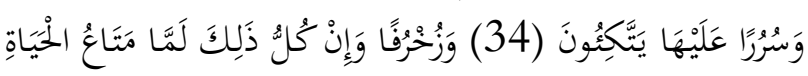

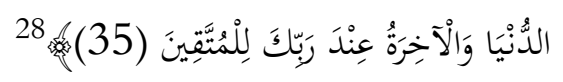

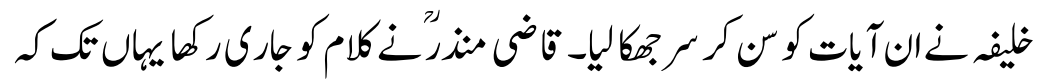

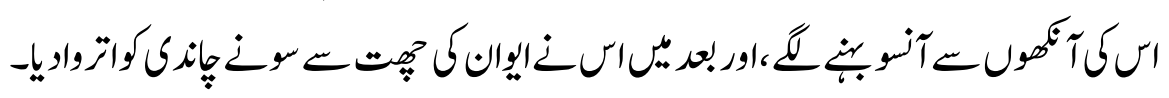

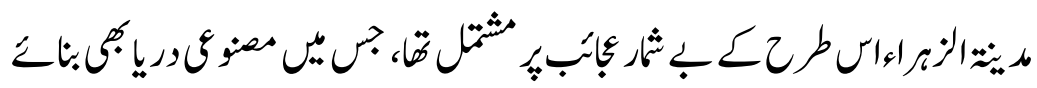

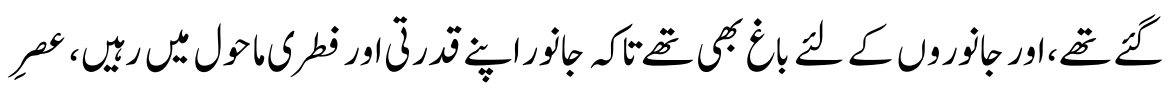

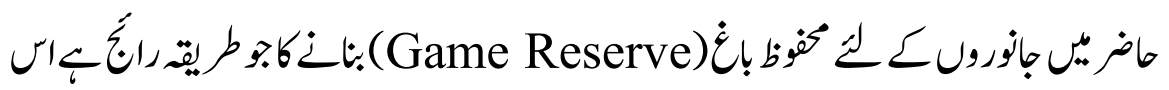

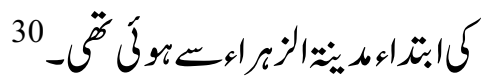
3ـقمراثبيليي

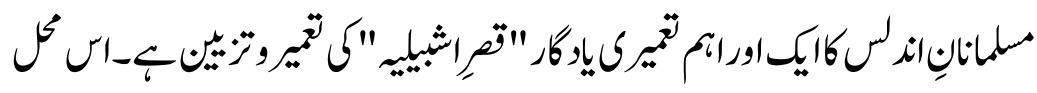

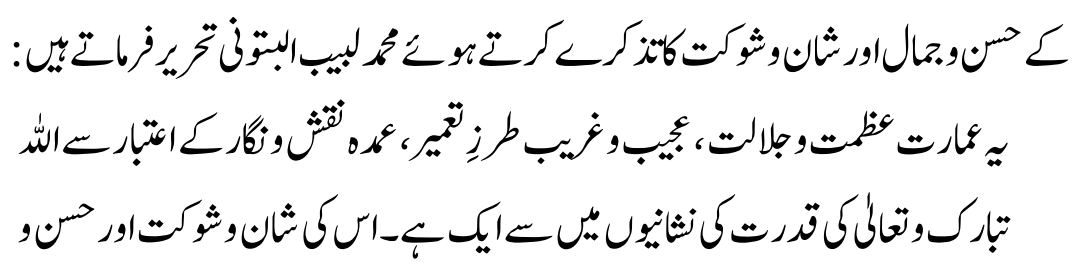




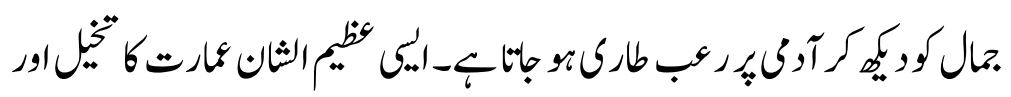

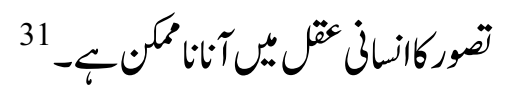
4-تمرالمراء تصوركاء

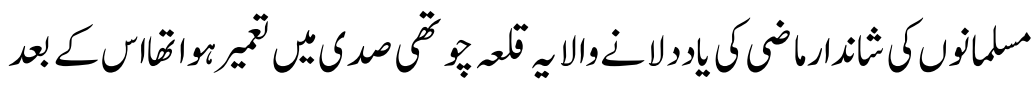

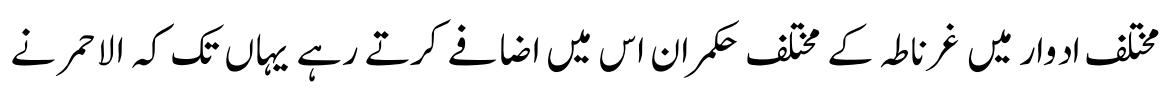

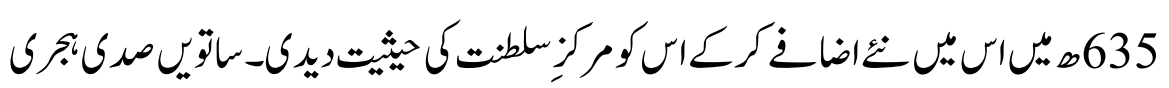

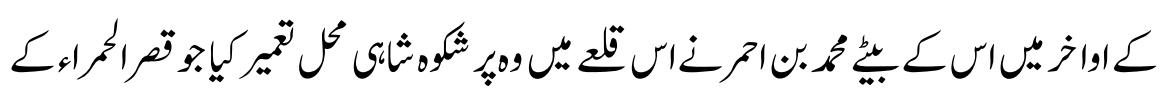

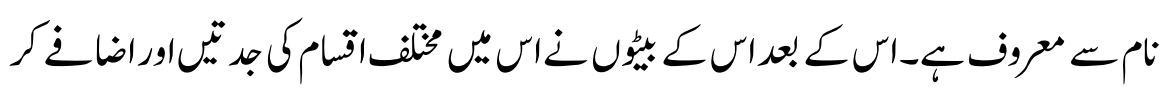

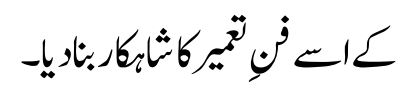

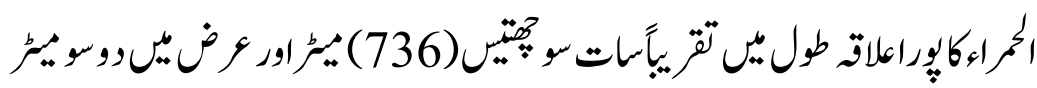

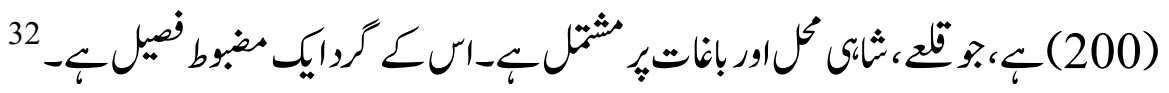

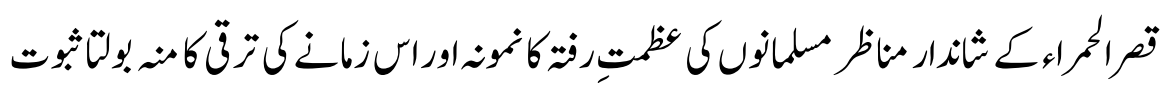

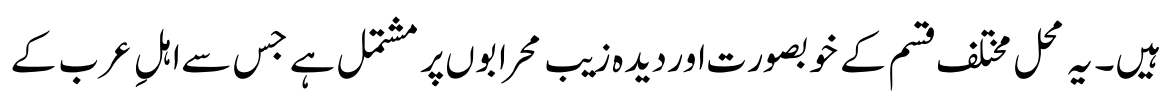

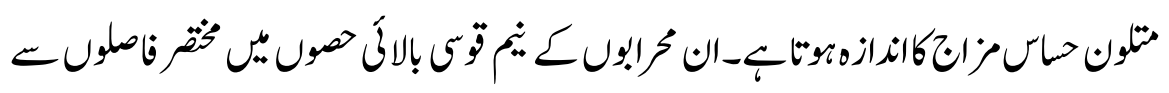

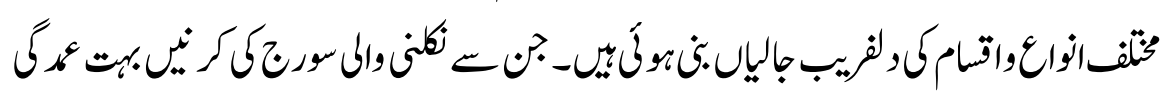

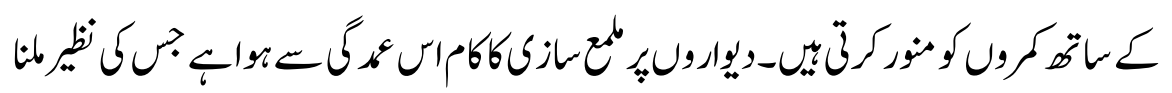

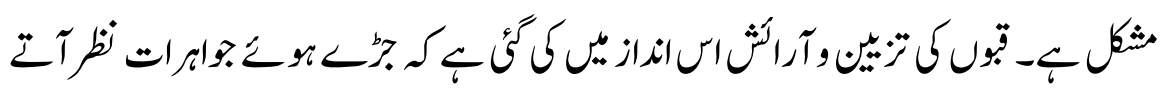

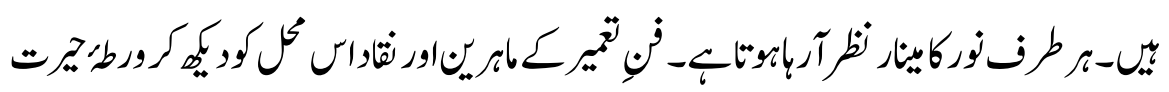

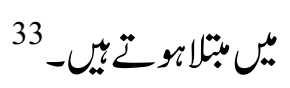

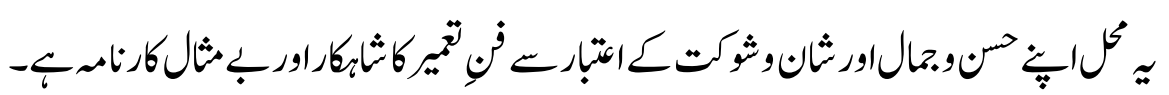




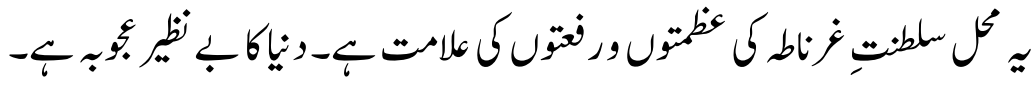

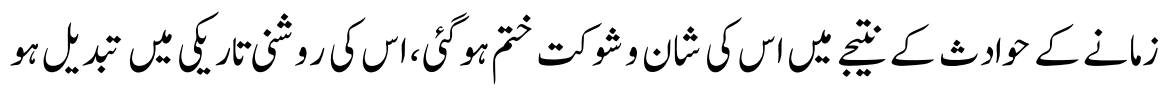

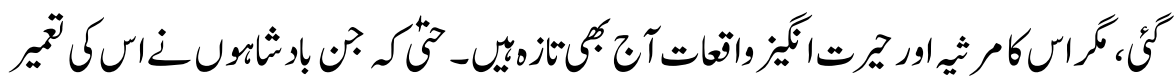

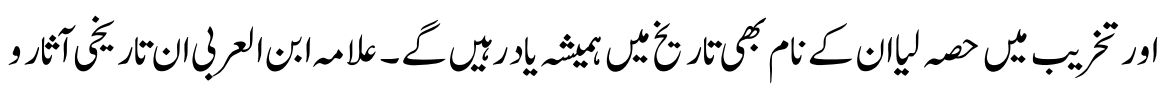

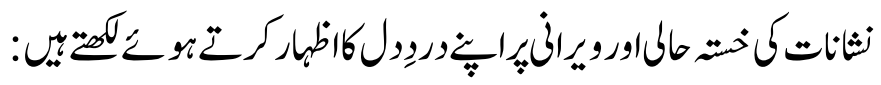

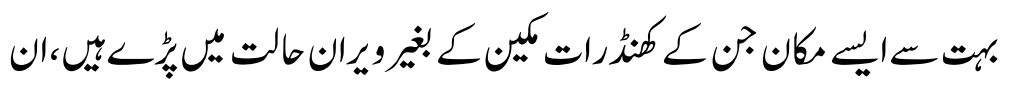

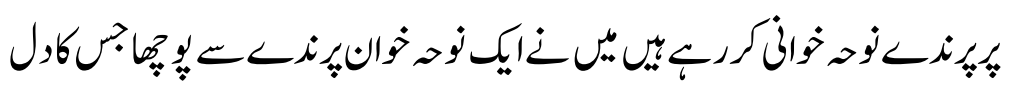

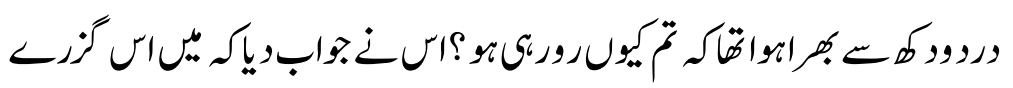

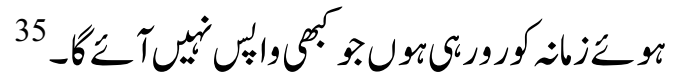
5-بنداوك تيمير

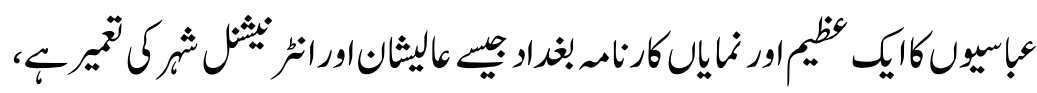

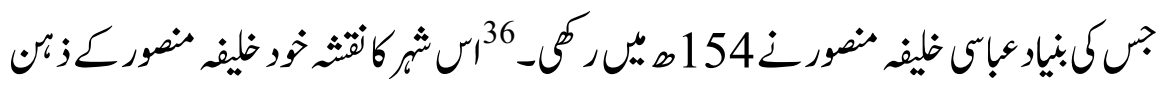

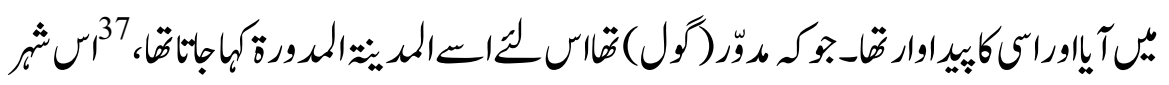

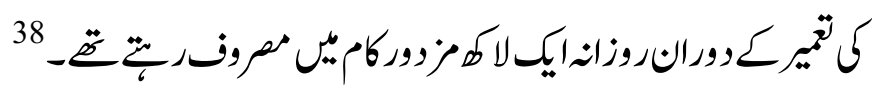

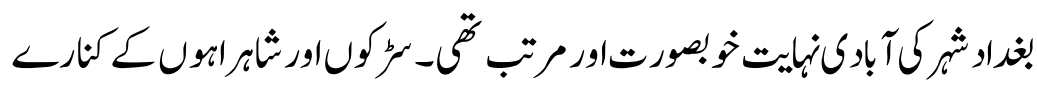

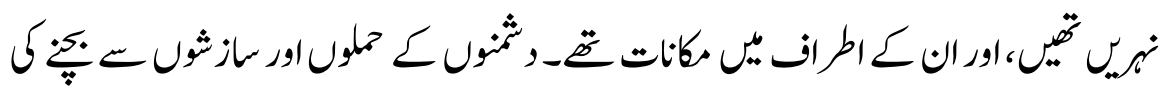

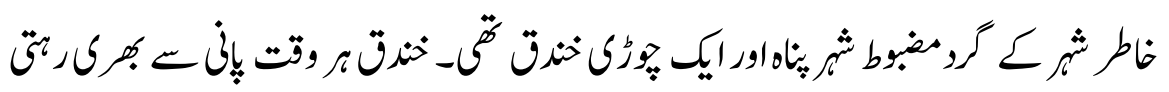

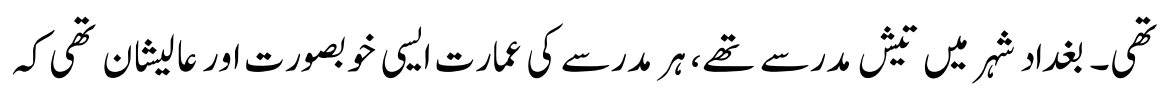

$$
\begin{aligned}
& \text { 6” }
\end{aligned}
$$

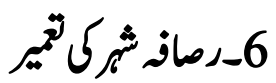

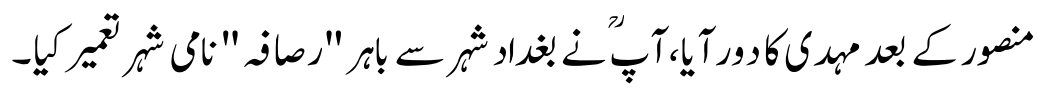

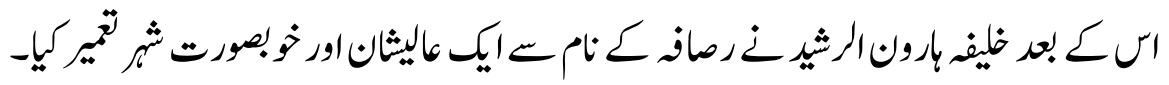




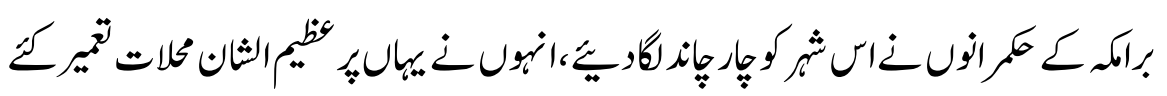

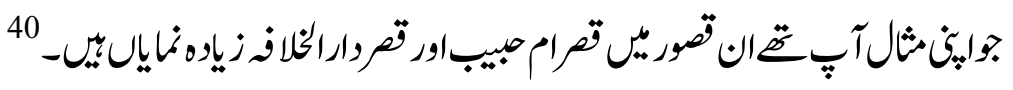
7

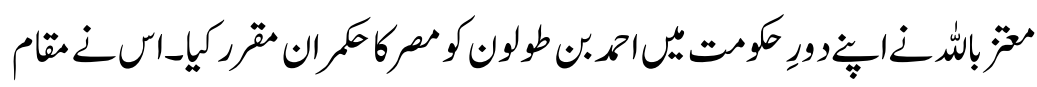

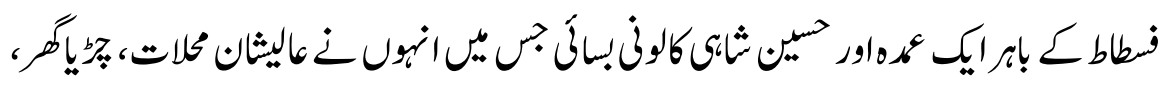

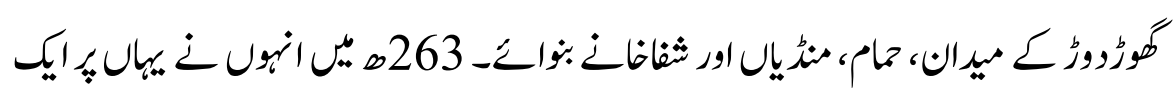

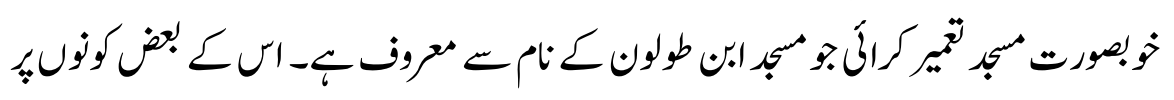

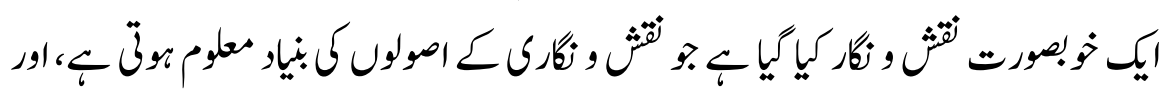

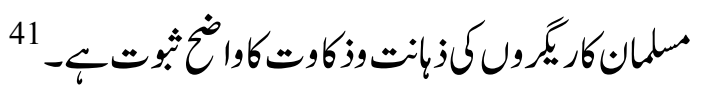
فاطقورو تميرى آثنر

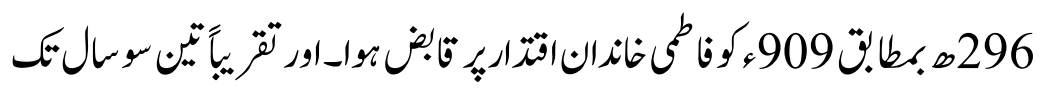

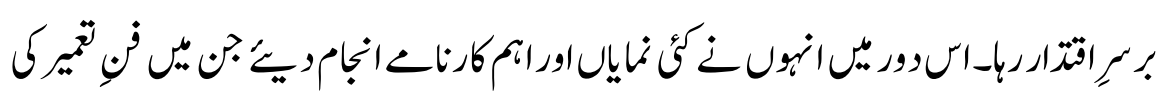

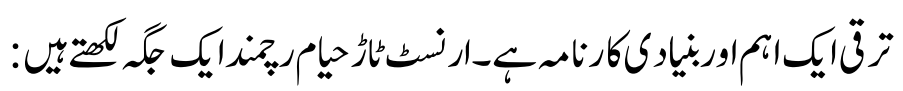

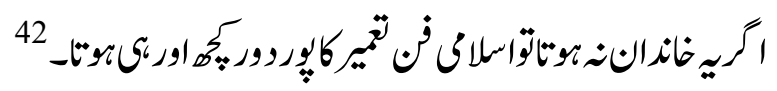

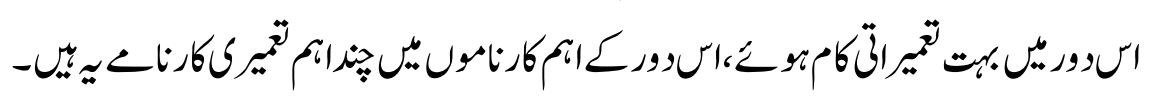
1

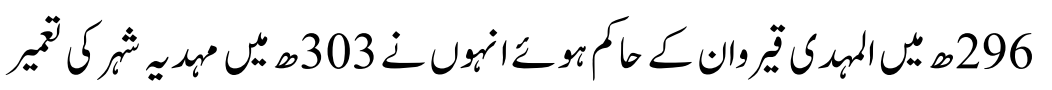

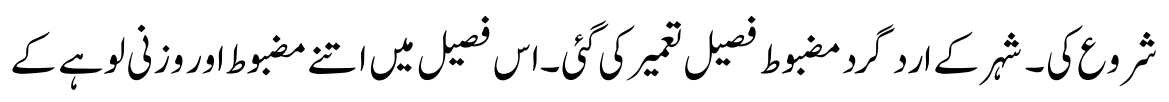

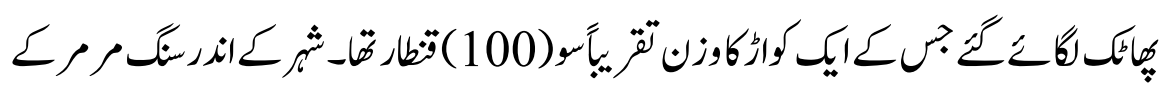

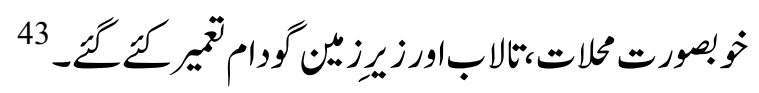

2- تايرهك تيم 


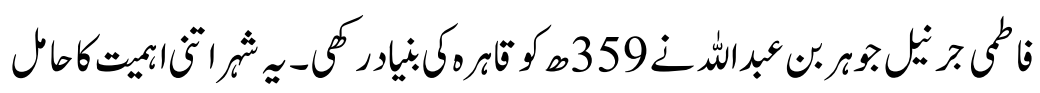

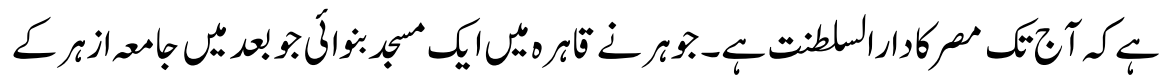

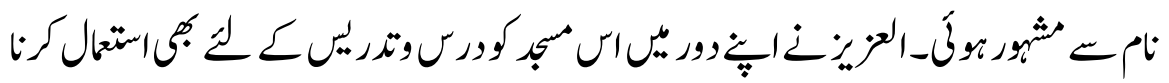
ثر و غكيا-

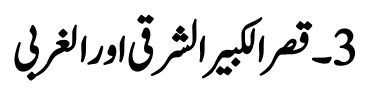

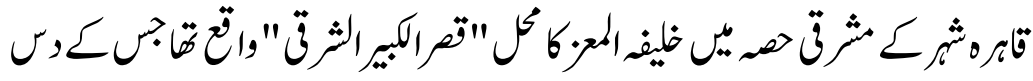

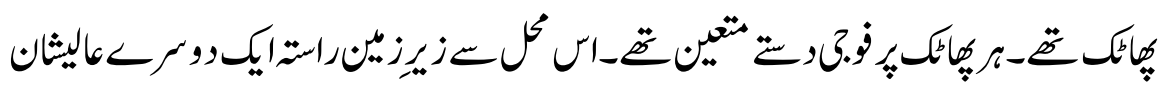

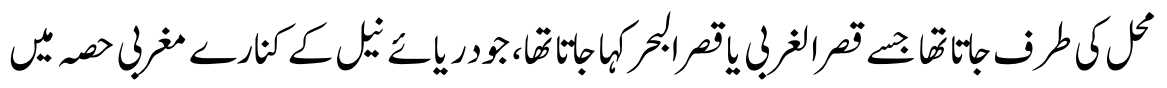
واتع خلامث:كث

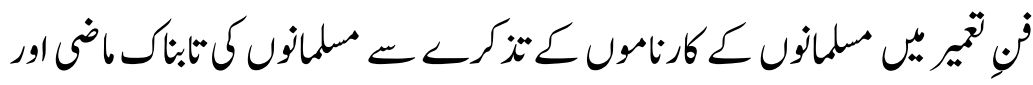

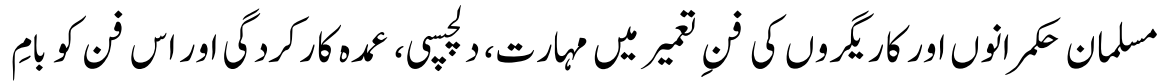

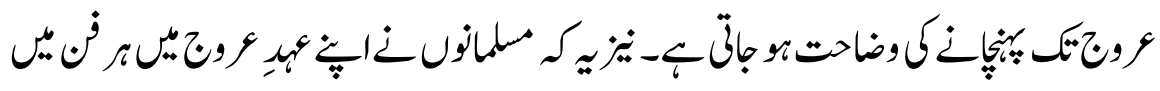

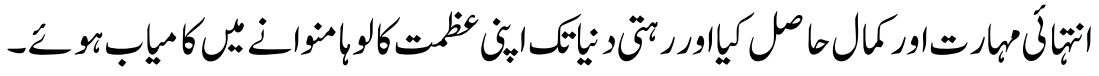
هاثَّو واله جات

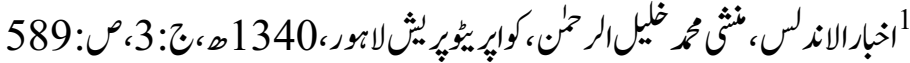

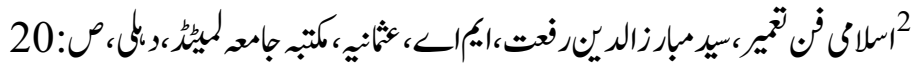

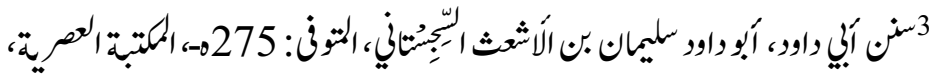

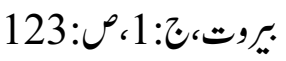




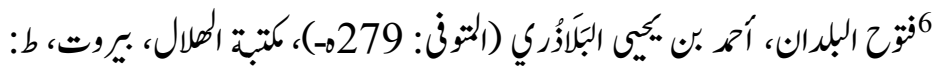
271: 1988

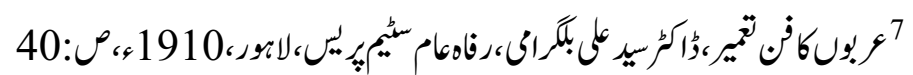

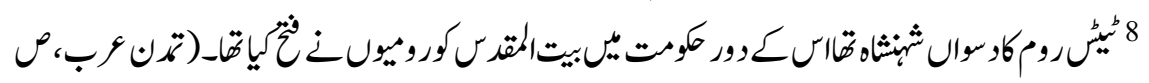

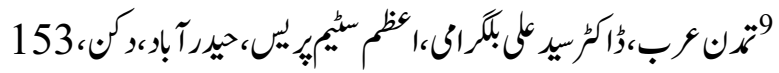

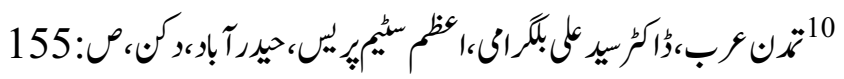

$$
\begin{aligned}
& \text { 11 }
\end{aligned}
$$

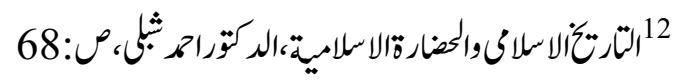

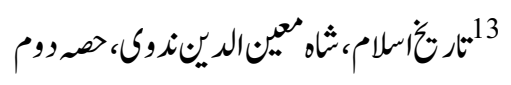

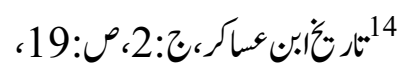

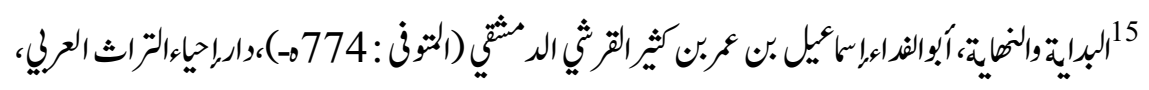

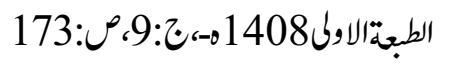

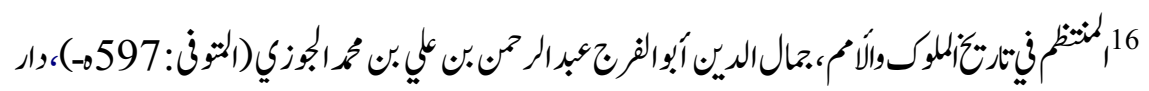

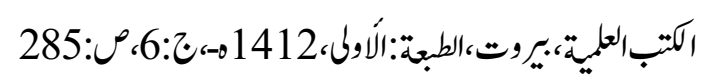

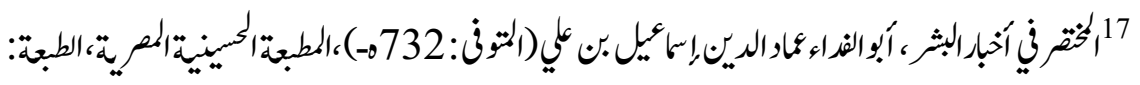

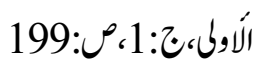

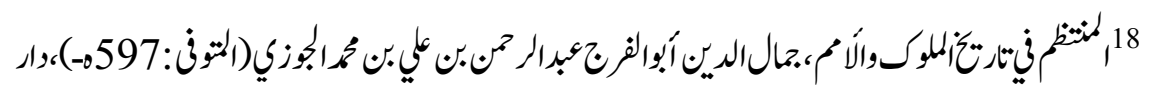

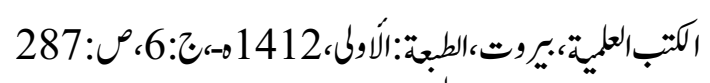
19

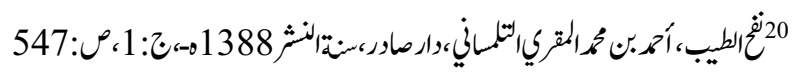

$$
\text { 21 }
$$

22

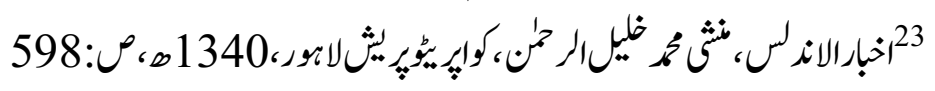




$$
\begin{aligned}
& \text { 24 }
\end{aligned}
$$

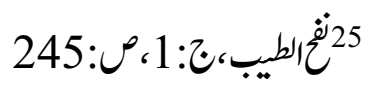

26 نفح الطيب،أمدبن محمدالمقري التلمساني، دارصادر، سنةالنشر 1388هـ، ج:

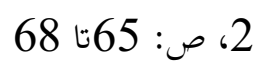

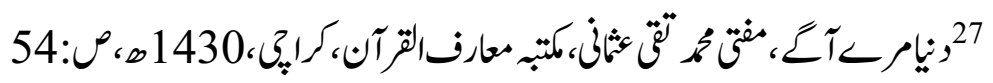

$$
28
$$

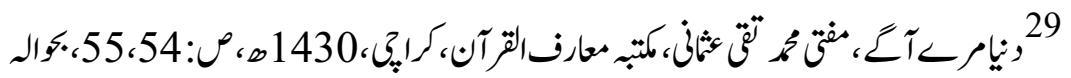

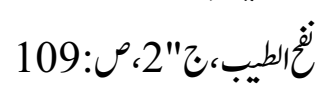

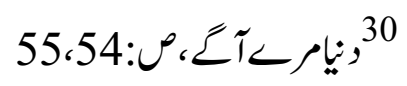

31 رحلة الاندلس، محمد لبيب البتونى، ص: 41

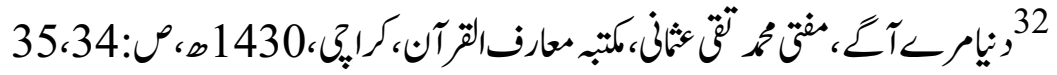
33

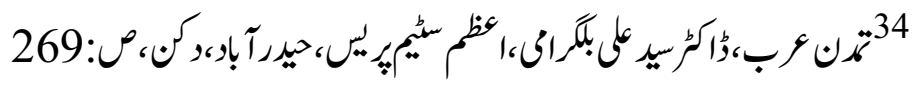

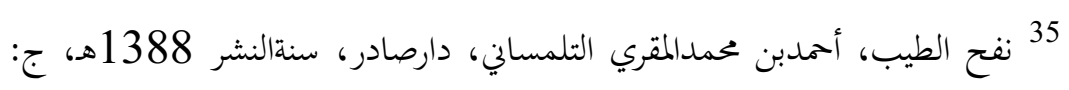
1 14، ص: 246

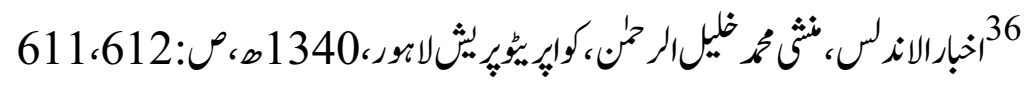

$$
37 \text { التاريخ الاسلامى والحضارة الاسلامية، ج:3، ص: } 304
$$

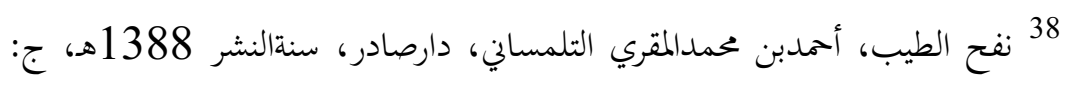

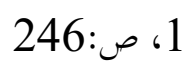

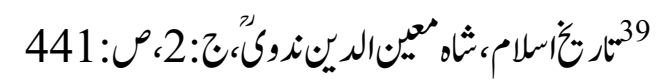
40 11

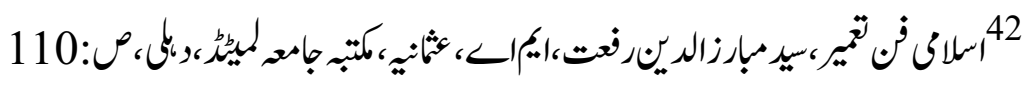




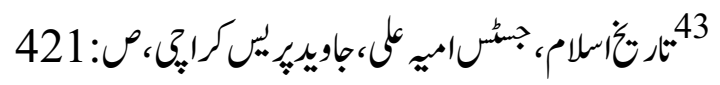

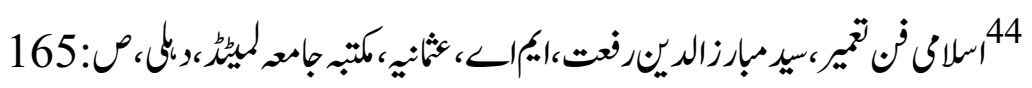

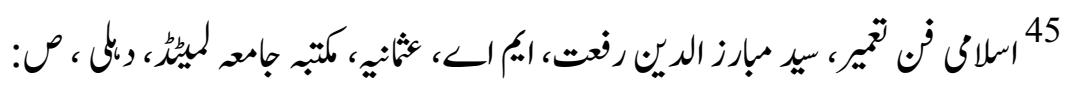
192،193 